\title{
Delayed effects on growth and marine survival of pink salmon Oncorhynchus gorbuscha after exposure to crude oil during embryonic development
}

\author{
Ron A. Heintz*, Stanley D. Rice, Alex C. Wertheimer, Robert F. Bradshaw, \\ Frank P. Thrower, John E. Joyce, Jeffrey W. Short
}

US National Marine Fisheries Service, Auke Bay Laboratory, 11305 Glacier Hwy, Juneau, Alaska 99801, USA

\begin{abstract}
We report delayed effects on the growth and marine survival of pink salmon Oncorhynchus gorbuscha, which were exposed to oil as embryos under conditions similar to those observed after the 'Exxon Valdez' oil spill. Pink salmon eggs were incubated in water that became contaminated with polynuclear aromatic hydrocarbons (PAHs) after percolating through gravel coated with weathered oil. Weathering ensured that the PAH composition of the water was dominated by alkyl-substituted naphthalenes and larger compounds. Most survivors of the exposures appeared healthy, and were released to the marine environment with coded-wire tags. Their survival was evaluated when they returned at maturity 2 yr later. Other survivors, also healthy in appearance, were retained in net pens to measure delayed effects on growth during the early juvenile stage. Pink salmon exposed to an initial concentration of total PAH equal to $5.4 \mathrm{ppb}$ experienced a $15 \%$ decrease in marine survival compared to unexposed salmon. A delayed effect on growth was measured in juvenile salmon that survived embryonic exposure to doses as low as $18 \mathrm{ppb}$ PAH. Reductions in juvenile growth could account for the reduced marine survival observed in the released fish. The demonstration of delayed effects on growth and survival support claims of delayed effects in pink salmon after the 'Exxon Valdez' oil spill, and indicate the potential for population-level effects resulting from embryonic exposure to oil.
\end{abstract}

KEY WORDS: Exxon Valdez $\cdot$ PAH $\cdot$ Pink salmon $\cdot$ Toxicity testing $\cdot$ Oil pollution $\cdot$ Delayed effects

\section{INTRODUCTION}

The impacts of oil spills on subsurface aquatic populations are difficult to measure, and are usually estimated from counts of mortalities observed immediately afterwards. However, individuals suffering from sublethal effects may not be counted among the number of mortalities, despite potential impacts on the individuals' probability of surviving and reproducing. Thus, delayed impacts that influence population recruitment

*E-mail: ron.heintz@noaa.gov may represent a significant but hidden component to the overall toxicity of a spill by limiting the productivity of affected populations. For example, individuals suffering sublethal effects that impair gamete production could diminish recruitment in the next generation while not displaying overt evidence of damage in the exposed generation. Sublethal impacts, which are normally difficult to measure, would be most profound in populations exposed during early developmental stages (Rosenthal \& Alderdice 1976). This was apparently the case for pink salmon Oncorhynchus gorbuscha populations exposed to beached oil during incubation after the 'Exxon Valdez' oil spill. These 
populations risked chronic exposure to polynuclear aromatic hydrocarbons (PAHs) leaching from the beached oil because their embryos and larvae develop for nearly 7 mo in streambeds that cut through contaminated beaches. Consequently, embryo mortality rates in contaminated streams were elevated above those in uncontaminated streams for $4 \mathrm{yr}$ after the oil spill (Bue et al. 1996, 1998).

More importantly, the survivors of these embryonic exposures experienced delayed impacts on gamete viability 4 yr after the spill. In 1993, gametes collected from adult pink salmon returning to contaminated and uncontaminated streams were transported to a hatchery and incubated in clean water (Bue et al. 1998). Pink salmon typically spawn in their natal streams at Age $2 \mathrm{yr}$, so those returning to contaminated streams were presumed to have survived embryonic exposure $2 \mathrm{yr}$ earlier. Gametes taken from adults homing to contaminated streams produced offspring with lower survival rates than gametes taken from fish returning to uncontaminated streams. The reduced reproductive ability of these fish may have resulted from genetic damage to germ cells, or impaired gonad development. Field observations such as these are exceedingly rare, and these observations are not corroborated by specific observations of the parental exposure levels.

Observations of delayed impacts in controlled laboratory studies are also rare, although they are logistically possible and exposure histories can be identified. In an earlier study at our laboratory, we reported immediate impacts on pink salmon larvae of low levels of PAH exposure (Marty et al. 1997). Survival was reduced at aqueous $\mathrm{PAH}$ concentrations of 32 parts per billion (ppb), and gonadal cell apoptosis was elevated at concentrations of $4.4 \mathrm{ppb}$. This impaired gonad development may ultimately be linked to diminished reproductive ability later in life. Other tissues demonstrated retarded development, suggesting the potential for delayed effects on growth and survival in fish exposed to a $4.4 \mathrm{ppb}$ concentration. However, the delayed impacts of these sublethal injuries were not measured. In a separate study, White et al. (1999) showed that larval exposure to $1.0 \mathrm{ppb}$ of benzo-apyrene can lead to heritable reductions in egg viability of fathead minnows.

In this report, we evaluate delayed effects following embryonic exposure of pink salmon to oil by combining controlled laboratory exposures with a release of fish to the wild environment. The homing behavior of pink salmon allows us to release exposed fish into the wild environment with the confidence that they can be recovered at maturity. By marking fish prior to their release, their exposure histories can be positively identified when they return. Specifically, the growth and marine survival of exposed pink salmon were evalu- ated to determine the severity of the delayed effects resulting from embryonic exposure to crude oil. The exposure system simulated the experience of pink salmon eggs in the intertidal reaches of streams in Prince William Sound, Alaska. Eggs were incubated to embryos in water contaminated with PAHs derived from oil whose composition was consistent with oil that landed on the beaches.

Three biological endpoints were measured to examine the impact of delayed effects: (1) the marine survival of exposed fish released to the wild, (2) the growth rate of pink salmon during the early part of their marine residence, and (3) the size of adult fish when they returned from the wild. Examination of marine survival was the primary objective because it integrates the impacts of all the sublethal effects in the most biologically meaningful way. Analysis of early marine growth was intended to identify the probable cause for mortality because rapid growth of juvenile pink salmon is thought to reduce their susceptibility to predation. Examination of the size at maturity was intended to verify any impacts detected during our evaluations of early growth.

The data presented in this report are derived from a suite of experiments performed on 2 different broods of pink salmon eggs using complementary designs. While survival and growth data were collected from both broods, the main objectives of the experiments emphasized the analysis of growth in 1 year and survival in the other. Experiments performed with the first brood year (1993) were designed to maximize the statistical power of the analysis of growth effects; 7 dose levels with $\sim 10000$ eggs per dose were used. The experiments with the second brood (1995) maximized the statistical power to resolve differences in marine survival between doses which required releasing large numbers of fish to ensure adequate numbers of returning adults; 3 dose levels with 120000 eggs per dose were used. The exposure levels and their immediate consequences for the first brood (1993) have been described previously (Heintz et al. 1999). Chemical analyses of dose levels and composition from the second brood are also presented to verify that exposure levels between years were comparable.

\section{MATERIALS AND METHODS}

Overview of pink salmon life history, exposure and incubation. Pink salmon Oncorhynchus gorbuscha are a commercially important species with an obligate $2 \mathrm{yr}$ life history. Adults spawn once in late summer in the intertidal or lower sections of coastal streams and die. Their eggs incubate overwinter and surviving fry emigrate to sea the following spring. Juveniles reside in 
saltwater for 18 mo before maturing and returning to their natal streams to spawn. Incubating pink salmon eggs and larvae remain buried in nests dug by their mothers in streambed gravel. Eggs incubate for approximately 2 mo before hatching as alevins, which complete the transition to fry over the remaining 4 to 5 mo. When fully formed fry emerge from the gravel, they immediately migrate to sea and begin feeding.

In Prince William Sound, Alaska, pink salmon returned to spawn in oil-contaminated streams 4 mo after the oil spill. Despite the evidence of effects, streambed gravels contained relatively little oil (Brannon et al. 1995). However, large deposits could be found on the stream banks (Murphy et al. 2000). Heintz et al. (1999) suggested an exposure mechanism whereby incoming tides force interstitial water upward through oil-contaminated gravels. PAHs that become dissolved in the interstitial waters are subsequently delivered to the lipid-rich eggs when the tide ebbs, and the interstitial water seeks the hydrodynamic minimum formed by the streambed.

We simulated these conditions by incubating pink salmon eggs in water contaminated with PAHs after percolating through gravel coated with Alaska North Slope crude oil. Prior to coating the gravel, the oil was heated at $70^{\circ} \mathrm{C}$ until the initial mass was reduced by $15 \%$. This process removed the volatile mono-aromatics so the composition of the oil used for exposure was consistent with that which made landfall in Prince William Sound (Bence \& Burns 1995). Whilst being tumbled in a cement mixer, the gravel was contaminated by spraying with known quantities of the weathered oil; it was then allowed to drain for $24 \mathrm{~h}$. After draining, the gravel was loaded into the incubators, and oil slicks and particulate matter were flushed from the incubators by flowing water through them for $48 \mathrm{~h}$. After flushing, fertilized eggs were added to the incubators, where they resided until the surviving fry emerged nearly 8 mo later.

The oil was never replenished during the exposure period, therefore the oil concentration on the gravel declined from the peak value initially observed. These changes in the exposure levels were monitored throughout incubation by evaluating $\mathrm{PAH}$ concentrations in samples of gravel, water and tissue. Initial samples of water and gravel were collected immediately before seeding the incubators with eggs, and tissues were collected after embryos had developed eyes (eyeing). Thereafter, samples of all 3 substrates were collected at hatching and emergence. Water supplies to the incubators alternated between fresh- and saltwater (salinity approximately $28 \mathrm{ppt}$ ) every $6 \mathrm{~h}$ with a $45 \mathrm{~min}$ transitional period between supplies. More details on the incubator design, fish culture and gravel contamination procedures can be found in Marty et al. (1997).
The concentrations of 40 PAHs were determined in the samples by gas chromatography and mass spectrometry in selected ion-monitoring mode following the procedures described in Short et al. (1996). PAHs were initially extracted from the samples in dichloromethane and purified in alumina/silica gel-column chromatography followed by size-exclusion highperformance liquid chromatography. Concentrations were determined by the internal standard method based on a suite of deuterated PAHs. Concentrations below experimentally determined method detection limits (MDLs) were treated as zero, and MDLs were generally $1 \mathrm{ppb}$ for tissue or gravel, and 1 to 8 parts per trillion for water. The accuracy of the hydrocarbon analyses was about $\pm 15 \%$ based on comparison with the US National Institute for Standards and Technology values; and precision, expressed as the coefficient of variation, was $\leq 20 \%$, depending on $\mathrm{PAH}$.

In this report, the term 'doses' will be used to refer to the initial water concentration of the sum of all the 40 PAHs (TPAH) measured in the incubator effluents expressed as ppb. The values for the doses will be preceded by a '<' because concentrations decreased exponentially after the exposures were initiated and the dose values therefore represent peak values. Doses used for the 1993 brood included control, <1.3, <3.6, $<7.8,<18.0,<31.0$ and $<48.0 \mathrm{ppb}$. The highest of these represents the maximum concentration we could obtain using our procedures. The remaining doses are intended to span the interval between the control and highest dose. The doses used for the 1995 brood were control, $<5.2$ and $<19.4 \mathrm{ppb}$ (Table 1); these replicate the lowest effective dose and next lower doses used for the 1993 brood. To describe the composition of oil on the gravel we use the weathering parameter $W$ described by Short \& Heintz (1997). This parameter quantifies the degree of weathering in an oil-contaminated sample, and permits identification of samples that have weathered to the same degree. When $w=0$, the composition of the oil is identical to the oil that

Table 1. Exposure levels for pink salmon Oncorhynchus gorbuscha embryos from 1995 brood tests. TPAH = summed concentrations of all polynuclear aromatic hydrocarbons. $W=$ weathering parameter, summarizing composition of oil (values near zero reflect oil devoid of mono-aromatics and similar in composition to oil spilled by 'Exxon Valdez' when it made landfall

\begin{tabular}{|lccc|}
\hline $\begin{array}{l}\text { Oil dose } \\
(\mathrm{ppm} \text { whole oil) }\end{array}$ & $\begin{array}{c}\text { Initial } \\
w\end{array}$ & $\begin{array}{c}\text { Initial gravel } \\
\text { TPAH (ppm) }\end{array}$ & $\begin{array}{c}\text { Initial aqueous } \\
\text { TPAH (ppb) }\end{array}$ \\
\hline Control & Control & 0.46 & 0.1 \\
83 & 1.1 & 0.86 & 5.2 \\
726 & 0.45 & 7.5 & 19.4 \\
\hline
\end{tabular}


made landfall in Prince William Sound (Bence \& Burns 1995). Increasing values of $w$ reflect increasing relative concentrations of PAHs with greater surface areas, including those with 2 or more alkyl substitutions.

Both brood years were incubated in the contaminated gravel for approximately $8 \mathrm{mo}$. Eggs were collected in September from a predominantly intertidal spawning stock of wild pink salmon and transferred to our hatchery for fertilization and incubation. Fertilized eggs were homogenized following procedures in Marty et al. (1997) to ensure a similar distribution of genotypes in each of the incubators. Equivalent weights of fertilized eggs were loaded into each of the incubators, where they remained until the following spring. Eyeing occurred about $40 \mathrm{~d}$ after fertilization, at which time the eggs were removed and counted to determine the initial numbers of exposed eggs and the number that survived early development. The live eggs were replaced in their incubators, where they remained until they emigrated the following spring. Emigration was volitional, and each day emigrants were counted and transferred to net pens for further culture in seawater. The immediate consequences of embryonic exposure have been reported in Heintz et al. (1999). Effects of oil exposure on embryonic mortality for the 1995 brood are reported in Wertheimer et al. (1997).

Experiments to determine marine survival. The experiment specifically designed to examine the effects of embryonic exposure to oil on marine survival was performed with the 1995 brood using the control, $<5.4$ and $<19.2$ doses. Fish from the 1995 brood that survived the exposure phase were tagged with halflength coded-wire tags (CWTs) between April 10 and May 18, 1996, using a design where the doses were randomly blocked on release time. The emergence period was arbitrarily divided into 7 time periods and tag lots of approximately 10000 fish representing each of the doses were released during each period. Fish were tagged in order of their emergence, so that a total of 21 separate groups were released, representing approximately 210000 fish. It took 3 to $5 \mathrm{~d}$ to completely tag all the fish in a time stratum, and fish from each dose were tagged during randomly selected portions of each of those days. After completing a time stratum, the fish were held for $30 \mathrm{~h}$ and then released. From each release group, 50 to 100 randomly selected individuals were sacrificed to inspect tag placement while tagging. Prior to release, a sample of approximately 600 fish were examined to determine tagretention rates for each tag lot. These rates ranged between 97.9 and $99.3 \%$ after $7 \mathrm{~d}$ (Wertheimer et al. 1997). Note that fish held for the $7 \mathrm{~d}$ tag-retention checks were not released.

Marine survival was determined by counting the number of fish that survived to maturity. This number included the number that successfully returned to the hatchery plus the number intercepted in local seine fisheries and those that strayed into local streams. The latter 2 numbers were estimated by sampling while the former was observed by counting all the fish arriving at our weir. The fishery sampling and methods used to estimate the number found straying into other streams are described in Wertheimer et al. (2000). Marine survival for a particular code lot was calculated as the total number of observed recoveries divided by the number released, and statistical analyses are based on these values. Estimates of return rates that account for the unsampled fractions of the other streams and the fishery can be found in Wertheimer et al. (2000).

The marine survival experiment with the 1993 brood year was a study on a much smaller scale. Fish exposed to the control, $<1.3,<7.8$ and $<18.0 \mathrm{ppb}$ doses were tagged between April 24 and 28, 1994, and released on May 3, 1994. Each dose was represented by 4 code lots and a total of 5454, 4749, 3771 and 2765 tagged fish, respectively. Each tag lot represented individuals from randomly selected pairs of incubators, so statistical analysis was approached as a 1-way ANOVA with 4 replicates for each dose. During tagging, 20 individuals from each holding pen were sampled to examine the quality of the fin marks and placement of the CWT. Afterwards, tagged fish were returned to the holding pens where they were fed until release. Tag-retention rates, determined on the day of release, ranged between 97 and $100 \%$ and were based on samples of approximately 200 fish from each code lot. Marine survival for a particular code lot from the 1993 brood was calculated as the total number of fish recovered with that tag code at our weir or found in a nearby stream divided by the number released. No attempt was made to account for tags recovered in local fisheries.

Experiments to examine early growth and size at maturity. The experiment specifically designed to examine the effects of embryonic exposure to oil on growth during the early marine phase was performed with the 1993 brood. During the peak of emergence, April 4 to 11, 1994, approximately 200 fry from each incubator were transferred to separate freshwater raceways. Selection during the peak reduced size variation, maximized fish health, and coordinated the initiation of feeding. Fish were retained in these raceways until their weight averaged $9 \mathrm{~g}$ when a randomly selected set of 42 fish were tagged with passively induced transponder (PIT) tags. These tags permitted unique identification of each fish so that they could be pooled together in larger net pens for evaluation of their growth. Tagging began on August 19, 1994, and continued for $6 \mathrm{~d}$. Initial forklengths and weights were recorded for each tagged fish, and they were returned to their raceways for recovery. On Sep- 
tember 21, 1994, the marked fish were pooled into 2 net pens located $5 \mathrm{~km}$ apart and deployed in saltwater. Fish in the net pens were examined 1 mo later and their final forklengths and weights were recorded. Growth was calculated by taking the difference between the natural logs of the initial and final weights, then dividing by the number of days that elapsed between tagging and the final sample. Growth rates were analyzed by ANOVA, with doses randomly blocked on the net pens. Experimental units were the incubators, so each dose was replicated 8 times, except for the highest dose which was replicated 15 times in each of the nets.

The growth study with the 1995 brood used fish retained from the marine survival experiments. Samples of fish from Time Strata 1, 2, 6 and 7 were cultured in a common net pen for approximately 10 mo after tagging, at which time they were sacrificed. The weight of each fish was recorded along with its tag code and exposure history. Growth rates were calculated using the same procedure as for the 1993 brood, but the initial weights were approximated from mean weights observed for each tag code at tagging. These means were determined from measurements taken from 100 randomly selected individuals from each dose in each time stratum at the time of tagging. The growth-rate measurements were examined by a random block design with doses blocked on release time, so that the tag codes were the experimental units.

The effects of embryonic exposure to PAH on size at maturity were examined by measuring all the mature adults captured at the weir. Male and female sizes

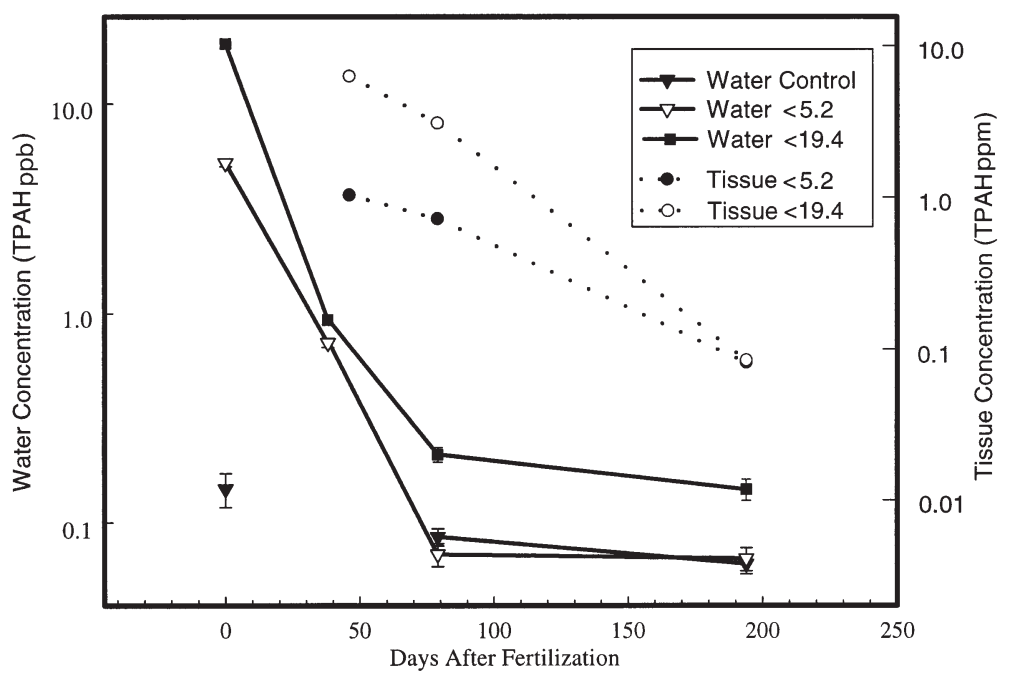

Fig. 1. Decline in mean $( \pm 1 \mathrm{SE})$ total aqueous PAH $(\mathrm{TPAH})$ concentrations (ppb) for each dose used for 1995 exposures, and resulting tissue concentrations (ppm) in Oncorhynchus gorbuscha eggs. Control water samples were not collected on Day 50, and control tissue levels are not shown. Symbols sometimes obscure error bars were examined independently. Lengths were recorded from the middle of the eye to the fork of the tail. Analysis of the data conformed to the design of the marine survival experiments, where the tag codes were the experimental units. Thus, the 1995 brood-year data were examined with random block design with each dose blocked on release time. The design for the 1993 brood dictated a 1-way ANOVA with dose replicated 4 times.

\section{RESULTS}

\section{Exposure levels, composition, and uptake}

The concentrations of PAHs in water decreased exponentially as the oil on the gravel weathered in both brood years. The composition in the water resembled the pattern found following the 'Exxon Valdez' oil spill (Short \& Harris 1996). The most volatile monoaromatics were evaporated from the oil prior to coating the gravel. Consequently, changes in water concentration reflected the decreasing relative concentrations of the most volatile of the 2- to 4-ring aromatics found on the gravel. In the 1995 test, the initial TPAH concentrations ranged from 5.2 to $19.4 \mathrm{ppb}$. Water concentrations of TPAH decreased to $<15 \%$ of their initial values in the first $38 \mathrm{~d}$ after fertilization of Oncorhynchus gorbuscha eggs (Fig. 1). Emergence began after another $156 \mathrm{~d}$, when TPAH levels in water samples collected from the $<5.2$ dose were indistinguishable from the controls, while those of the $<19.4$ dose were $0.1 \mathrm{ppb}$.

The PAH composition of the $<5.2$ and $<19.4$ doses differed slightly as a result of differences in the oil-film thicknesses on the gravel. Prior to loading the incubators with eggs, the gravel was flushed with water for $48 \mathrm{~h}$. This flushing caused a greater degree of weathering in the thinner film of oil on the gravel used for the $<5.2$ dose than for the $<19.4$ dose. Consequently, the initial relative concentrations of the alkyl-substituted dibenzothiophenes, phenanthrenes and chrysenes were greater in the water contaminated by the $<5.2$ dose than with the $<19.4$ dose (Table 2). Compositional differences between the $<5.2$ and $<19.4$ doses were consistent with differences observed for the 1993 brood exposures. The composition of the oil on the gravel used for the $<19.4$ dose was similar to that used for the $<18.0$ dose in 1993; values of the weathering parameter $w$ for these doses were 0.45 and 0.6 , respectively. The low values for 
Table 2. Mean relative concentrations $( \pm \mathrm{SE})$ of polynuclear aromatic hydrocarbons (PAH) in incubator effluents at time 1995 brood exposures of Oncorhynchus gorbuscha began. Relative concentrations are expressed as percentage of total PAH concentration; nd = analyte not detected

\begin{tabular}{|c|c|c|}
\hline $\mathrm{PAH}$ & $<5.2$ dose & $<19.4$ dose \\
\hline Naphthalene & nd & $0.65 \pm 0.06$ \\
\hline 2-methylnaphthalene & $1.30 \pm 0.07$ & $8.28 \pm 0.13$ \\
\hline 1-methylnaphthalene & $1.23 \pm 0.04$ & $7.59 \pm 0.11$ \\
\hline Biphenyl & $0.52 \pm 0.04$ & $1.69 \pm 0.02$ \\
\hline C-2 naphthalenes & $12.3 \pm 0.9$ & $28.0 \pm 0.3$ \\
\hline C-3 naphthalenes & $21.1 \pm 0.9$ & $19.4 \pm 0.1$ \\
\hline C-4 naphthalenes & $8.50 \pm 0.02$ & $4.18 \pm 0.05$ \\
\hline Acenaphthylene & $0.07 \pm 0.01$ & $0.02 \pm 0.01$ \\
\hline Acenaphthene & $0.33 \pm 0.05$ & $0.26 \pm 0.01$ \\
\hline Fluorene & $1.45 \pm 0.12$ & $1.74 \pm 0.07$ \\
\hline C-1 fluorenes & $3.78 \pm 0.14$ & $2.69 \pm 0.1$ \\
\hline C-2 fluorenes & $4.35 \pm 0.21$ & $1.84 \pm 0.06$ \\
\hline C-3 fluorenes & $1.84 \pm 0.24$ & $0.52 \pm 0.1$ \\
\hline Dibenzothiophene & $3.24 \pm 0.13$ & $3.76 \pm 0.01$ \\
\hline C-1 dibenzothiophenes & $3.88 \pm 0.09$ & $2.19 \pm 0.01$ \\
\hline C-2 dibenzothiophenes & $2.86 \pm 0.16$ & $1.01 \pm 0.02$ \\
\hline C-3 dibenzothiophenes & $1.56 \pm 0.37$ & $0.37 \pm 0.04$ \\
\hline Phenanthrene & $5.37 \pm 0.31$ & $4.75 \pm 0.04$ \\
\hline Anthracene & $0.21 \pm 0.01$ & $0.09 \pm 0.01$ \\
\hline C-1 phenanthrenes & $11.5 \pm 0.2$ & $6.40 \pm 0.01$ \\
\hline C-2 phenanthrenes & $7.50 \pm 0.42$ & $2.78 \pm 0.08$ \\
\hline C-3 phenanthrenes & $3.55 \pm 0.74$ & $0.91 \pm 0.08$ \\
\hline C-4 phenanthrenes & $0.89 \pm 0.24$ & $0.22 \pm 0.02$ \\
\hline Fluoranthene & $0.51 \pm 0.15$ & $0.07 \pm 0.01$ \\
\hline Pyrene & $0.38 \pm 0.05$ & $0.09 \pm 0.01$ \\
\hline C-1 fluoranthenes & $0.39 \pm 0.03$ & $0.13 \pm 0.01$ \\
\hline Benz[a]anthracene & $0.05 \pm 0.01$ & $0.04 \pm 0.03$ \\
\hline Chrysene & $0.28 \pm 0.01$ & $0.06 \pm 0.02$ \\
\hline C-1 chrysenes & $0.23 \pm 0.05$ & $0.05 \pm 0.01$ \\
\hline C-2 chrysenes & $0.09 \pm 0.03$ & $0.02 \pm 0.01$ \\
\hline C-3 chrysenes & $0.06 \pm 0.01$ & $0.01 \pm 0.01$ \\
\hline C-4 chrysenes & $0.04 \pm 0.01$ & $0.01 \pm 0.01$ \\
\hline Benzo-b-fluoranthene & $0.09 \pm 0.01$ & $0.03 \pm 0.01$ \\
\hline Benzo-k-fluoranthene & $0.07 \pm 0.01$ & $0.02 \pm 0.01$ \\
\hline Benzo-e-pyrene & nd & nd \\
\hline Benzo-a-pyrene & $0.06 \pm 0.01$ & $0.02 \pm 0.01$ \\
\hline Perylene & nd & nd \\
\hline Indeno-123-cd-pyrene & $0.17 \pm 0.01$ & $0.04 \pm 0.01$ \\
\hline Dibenzo-a,h-anthracene & $0.14 \pm 0.01$ & $0.04 \pm 10.01$ \\
\hline Benzo-g,h,i-perylene & $0.11 \pm 0.01$ & $0.03 \pm 0.01$ \\
\hline
\end{tabular}

these samples indicates that their compositions were similar to oil devoid of mono-aromatics such as benzene, toluene and xylene, but with high relative concentrations of naphthalenes and less substituted phenanthrenes. The initial value for $w$ calculated for the $<5.2$ dose used in 1995 was 1.09 , which was comparable to the 1.5 value recorded for the $<7.8$ dose in 1993 (Heintz et al. 1999).

Peak tissue concentrations were observed in the eyed egg samples collected $46 \mathrm{~d}$ after fertilization (Fig. 1) when yolk content was still high. Tissue PAH levels subsequently decreased as development pro- gressed, and $198 \mathrm{~d}$ after fertilization, when emergence began, PAH loads were $<10 \%$ of their peak values. This decrease resulted from the loss of PAHs from tissues that paralleled losses in incubator effluent (Heintz et al. 1999). Its unlikely that decreased PAH burdens reflected dilution by increased tissue mass, because no feeding occurs during incubation and fry weights are similar to unfertilized egg weights. The TPAH concentrations in the eyed eggs ranged from $0.3 \mathrm{ppm}$ in the unexposed eggs to 1.0 and $6.3 \mathrm{ppm}$ in the eggs from the $<5.2$ and $<19.4$ doses, respectively. This timing and level is in accordance with the more detailed analysis presented for the 1993 brood fish in Heintz et al. (1999).

\section{Effect of embryonic exposure on marine survival}

Fewer exposed fish from the 1995 brood survived the marine environment and returned as mature adults compared to the unexposed fish $(\mathrm{p}<0.0001)$. On average, $1.3 \pm 0.3 \%$ of the control fish were recovered compared to $1.1 \pm 0.2$ and $0.8 \pm 0.2 \%$ for the $<5.2$ and $<19.4$ doses, respectively (Fig. 2). While these changes in survival might appear too small to be significant, they were both statistically and biologically significant in the returning adults, more than 900 control fish were recovered compared to 757 and 575 for the $<5.2$ and $<19.4$ doses, respectively. The marine survival observed for the $<5.2$ dose was significantly lower than the control rate $(p=0.012)$. Mean recovery rates differed significantly among the different release times ( $p<0.001)$, with the first 2 release times having the greatest mean recovery: $1.7 \pm 0.3$ and $1.9 \pm 0.2 \%$, respectively. Hence, it was important in the experimental design that each release group contained approximately equal numbers of control and dosed fish. The design did not allow testing for the interaction between dose and release time. However, the $<19.4$ dose had the lowest mean recovery rate for all 7 release times, and the $<5.2$ dose had the intermediate mean rate in 6 of the 7 release times.

Most fish were recovered as returns to the hatchery, and some in the fishery, but distribution of the recoveries among the different recovery locations did not depend on dose. Weir recoveries accounted for $84.2 \pm$ 1.9 and $87.4 \pm 1.3 \%$ of all the tag recoveries for the $<5.2$ and $<19.4$ doses, respectively, and the controls had an intermediate recovery rate of $84.7 \pm 1.0 \%$. Similarly, recoveries in the fisheries accounted for $10.5 \pm$ 1.3 to $13.0 \pm 1.0 \%$ of all tags recovered for the $<5.2$ and control doses, respectively, while fishery recoveries accounted for $13.2 \pm 2.1 \%$ of all $<19.4$ dose recoveries. The remainder were recovered in non-natal streams (Wertheimer et al. 2000). 

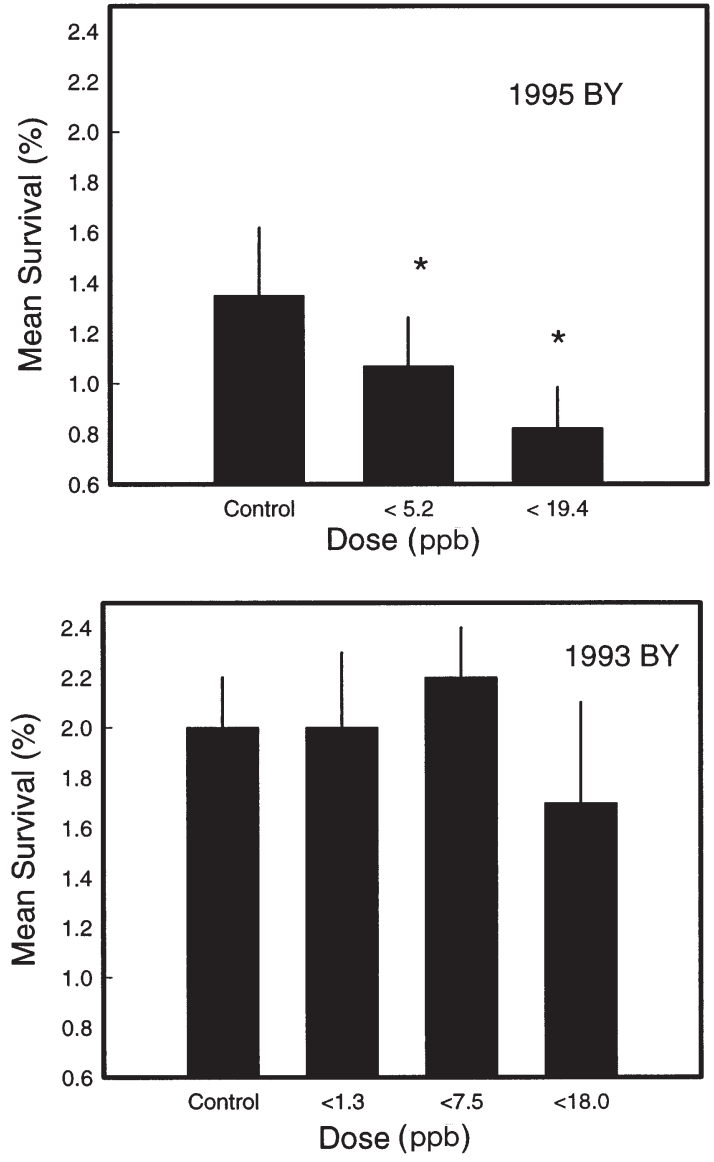

Fig. 2. Oncorhynchus gorbuscha. Average recovery rates ( $\pm 1 \mathrm{SE}$ ) of exposure groups released for 1995 brood and 1993 brood marine survival experiments. Values for the 1995 brood are mean recoveries of 7 tag lots from each dose with release sizes of approximately 10000 fish per lot; values for 1993 brood are means of 4 lots per dose with release sizes of $<1500$ fish per lot. ${ }^{*}=$ doses with significantly lower recovery rates than control. BY: brood year

Results of the less extensive marine survival experiment performed with the 1993 brood corroborate the observation of reduced survival in the $<19.4$ dose from the 1995 brood. The mean return rate for the 1993 brood was lowest for fish initially exposed to the $<18.0$ dose (Fig. 2). Recovery rates for the doses analogous to the those used for the 1995 brood were $2.0 \pm 0.2,2.2 \pm 0.3$ and $1.7 \pm$ $0.4 \%$ for control, $<7.8$ and $<18.0$ doses, respectively. The ANOVA failed to detect a difference among these means $(p=0.648)$. The inability of the ANOVA to detect a difference in survival for this brood year (with low release numbers and returns) is consistent with the lower statistical power of this experiment. Factors that led to lower statistical power in the 1993 brood experiment included reduced numbers of replicates and small numbers of releases, resulting in a number of recoveries that was onetenth that of the 1995 brood experiment.
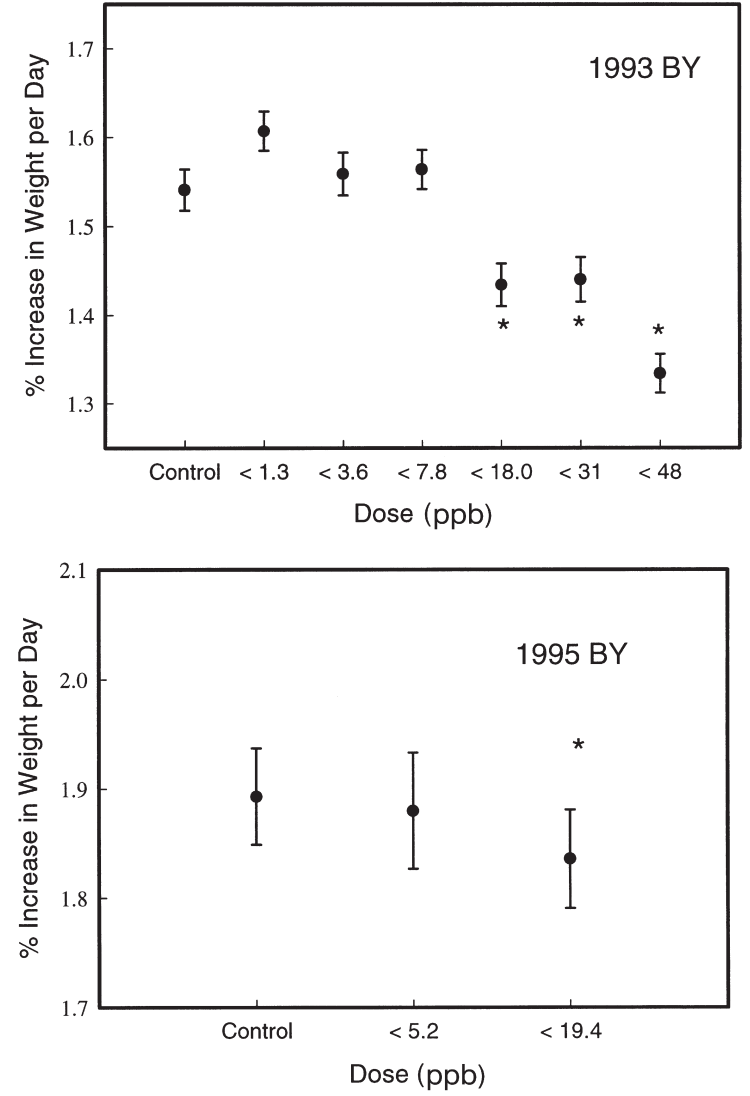

Fig. 3. Oncorhynchus gorbuscha. Mean growth rate ( $\pm 1 \mathrm{SE})$ of 1993 brood fish 4 to 6 mo after PAH exposures ended and of 1995 brood fish during first 10 mo after exposure. Means shown for 1993 brood were calculated by averaging the mean growth rates observed in each of the 8 incubators (15 for $<48$ ppb dose) replicating each dose; means for 1995 brood were obtained by averaging 4 mean growth rates observed for fish from different emergence times. See 'Materials and methods' for details on experimental designs. * = doses with significantly different growth than control. BY: brood year

\section{Early marine growth in exposed fish}

The 1993 brood growth-experiment demonstrated the dependence of early marine growth on embryonic exposure level ( $p<0.001)$ (Fig. 3). Unexposed fish increased their mass by an average of $1.54 \pm 0.02 \% \mathrm{~d}^{-1}$ compared to $1.33 \pm 0.02 \%$ for the fish exposed to the $<48.0$ dose. This meant that despite their having equal weights initially ( $p=0.590), 200 \mathrm{~d}$ after the exposures ended, control fish averaged $23.0 \pm 0.9 \mathrm{~g}$ compared with fish exposed to the $<48.0$ dose which averaged $21.5 \pm 0.6$. If the relative difference in these growth rates were maintained until maturity, an additional $300 \mathrm{~d}$, then fish exposed to the $<48.0$ dose would be expected to weigh approximately half as much as control fish. While their weights differed by $5 \%$ at the end of the experiment, their lengths were nearly equal, 
varying between $144 \pm 1$ and $141 \pm 1 \mathrm{~mm}$, for the control and $<48.0$ dose, respectively. The $<18.0$ dose was the lowest dose, with average growth less than the control $(\mathrm{p}=0.021)$.

Growth of the 1995 brood held in net pens for $300 \mathrm{~d}$ after exposure ended also demonstrated a dependence on embryonic exposure level $(p=0.0002)$. Fish from the control dose grew an average of $1.89 \pm 0.01 \% \mathrm{~d}^{-1}$ compared with $1.88 \pm 0.01$ and $1.84 \pm 0.01 \% \mathrm{~d}^{-1}$ for the $<5.2$ and $<19.4$ doses, respectively (Fig. 3). A significant difference in growth rate between the controls and $<19.4$ dose $(p=0.0001)$ meant that the final weight of the exposed fish was $52.3 \pm 1.9 \mathrm{~g}$ compared with 61.1 $\pm 3.4 \mathrm{~g}$ for the control fish, despite similar initial sizes ( $p=0.860$ ). Lengths were not recorded for these fish. As with the 1993 brood, these relatively small differences in growth rate might appear biologically insignificant, but when extrapolated over a the remaining life of the fish, they translate to large differences in size at maturity. Another 7 mo of growth at the observed rates would result in fish from the $<19.4$ dose being $33 \%$ lighter at maturity than the controls.

\section{Effect of embryonic exposure on size at maturity}

Differences in size at maturity were not apparent between different dose groups released to the wild. Neither the lengths nor weights of returning males ( $p>$ 0.198) or females ( $p>0.202$ ) differed among the exposure groups in both brood years. In contrast to the growth experiments performed on captive fish where all control and exposed fish survived to the end of the growth measurements, the fish released to the wild were measured when they returned and survival may have depended on growth or size at a given age. Exposed fish should have been much lighter than control fish, based on the differences in average daily growth rates observed in the growth experiments. However, the most extreme difference in weights was observed between the control and $<18.0$ dose males from the 1993 brood, who differed by $10 \%$, decreasing from $1304 \pm 41$ to $1150 \pm 48 \mathrm{~g}$, respectively. The lengths and weights of the remaining exposure groups were all similar, differing by no more than $5 \%$ in a given brood year.

\section{DISCUSSION}

Exposure of embryonic Oncorhynchus gorbuscha to PAH concentrations in the low ppb produced sublethal effects in pink salmon that led to reduced growth and marine survival. These data demonstrate that the contributions of delayed mortality can be a significant component to total mortality resulting from exposure to oil. Therefore, evaluation of oil toxicity by examination of the short-term consequences underestimates the impacts of oil pollution. For example, Heintz et al. (1999) reported a $25 \%$ reduction in survival during incubation for 1993 brood fish exposed to the $<18.0$ dose. Between the end of the exposure and maturity, survival was further reduced by another $15 \%$, resulting in the production of $40 \%$ fewer mature adults than the unexposed population. Thus, the true effect of the exposure on the population was $>50 \%$ greater than was concluded after evaluating the immediate effects.

The effects described here resulted from exposure to PAHs with 2 to 4 rings, compounds whose impact on subsurface aquatic organisms after oil spills have been assumed to be inconsequential. In contrast to the data presented here, pink salmon fry exposed to the watersoluble fraction of oil for $10 \mathrm{~d}$ had the same marine survival as unexposed fry (Birtwell et al. 1999). That study simulated conditions posited to be encountered by pink salmon fry in the first few days after a spill, when highly volatile mono-aromatic hydrocarbons rapidly dissolve into water below the oil slick. However, Wertheimer \& Celewycz (1996) and Willette (1996) demonstrated that pink salmon fry migrating through an oil spill are more likely to be exposed to multi-ring aromatics, with profound impacts on their growth and marine survival (Geiger et al. 1996). Thus, exposure of sensitive life stages to low concentrations of highly toxic multi-ring PAHs poses a greater risk to fish populations after a spill than exposure to mono-aromatics. This is consistent with the observed loss of billions of herring larvae (Brown et al. 1996) after the monoaromatic compounds had evaporated from the oil spilled by the 'Exxon Valdez'.

The absence of size differences in the exposed fish that survived to maturity could have resulted from size-dependent mortality during their marine residence, or from compensatory growth relative to that of the unexposed fish. Our observations of reduced growth indicate that the size of mature fish from the control and $<19.4$ dose should have differed by nearly $30 \%$. The failure of these fish to differ in size at maturity may have resulted from size-dependent mortality, as suggested by the fewer recoveries of exposed fish. Slower-growing pink salmon are likely to be more vulnerable to predation because their small size makes them susceptible to a greater number of predators, and less able to evade attacking predators (Lundvall et al. 1999). Alternatively, compensatory growth would result when a sufficient number of exposed fish have died, thereby decreasing the density of conspecific competitors. However, the number of exposed fish that survived is trivial in comparison with the large number of conspecifics they likely encountered during their 
marine migration. Thus, compensatory growth is a less likely explanation for the absence of a size difference at maturity than size-selective predation.

The slower growth rates observed during the early marine residence are likely to be the result of a variety of sublethal biochemical effects. Growth measurements integrate a variety of physiological processes, and it is unlikely that slower growth is the result of energetic deficiency brought on by the need to metabolize and depurate oil (Moles et al. 1987). We observed reduced growth long after the exposures ended, and $\mathrm{PAH}$ loads in tissues were minimal at emergence. More likely, it results from biochemical impairments acquired during early development. Roy et al. (1999) described mutagenic effects of oil on pink salmon incubated under conditions similar to those described here. Consequently, reduced growth could conceivably result from damage to DNA which could impair gene regulation, divert energy to incipient carcinomas, or impair activity of enzymes responsible for modulating growth or foraging. It is important to note that length of exposed fish was much less affected than weight. Reduced lengths would indicate an impaired ability to grow bony structures. Reduced weight suggests variation in the size of organs and fluid volumes, and represents a greater variety of biochemical impairments.

The delayed effects resulting from embryonic exposure to PAHs reported here indicate that mortality levels reported for salmon streams contaminated by the 'Exxon Valdez' underestimated the total mortality induced by exposure. Measurements of mortality in oil-contaminated streams reported by Bue et al. (1996) only accounted for direct observations of dead embryos in samples collected from streams, and failed to account for the number of delayed mortalities that inevitably followed the embryonic exposures. Likewise, estimates of lost production in the years following the spill (Geiger et al. 1996) failed to account for delayed effects in those broods that were exposed to oil during incubation. Maki et al.'s (1995) inability to detect differences in the recruit per spawner ratios between oiled and unoiled streams indicates either these effects were not catastrophic, or the methods used to detect them were underpowered. Geiger et al. (1996) demonstrated that the oil had a detectable, but not catastrophic impact on the productivity of pink salmon populations in southwestern Prince William Sound. Thus, it seems likely that the methods employed to determine the recruit per spawner ratios reported by Maki et al. (1995) were insufficiently powered. This is consistent with their failure to distinguish between homing and straying salmon in their study streams, and straying salmon can account for $>25 \%$ of the pink salmon in some streams (Sharp et al. 1994). Deficiencies in the statistical power of Exxon- sponsored sampling designs have been reported elsewhere (Peterson et al. 2001).

When oil contaminates natal habitats, the immediate effects in one generation may combine with delayed effects in another to increase the overall impact on the population. This is demonstrated by the pink salmon in Prince William Sound, which incubated downstream from persistent oil reservoirs for years after the 'Exxon Valdez' oil spill. Observations in 1991, 2 yr after the spill, revealed the greatest discrepancy in mortality between oiled and unoiled streams (Bue et al. 1996). This difference is partly due to observations of elevated mortality in stream sections that were not contaminated by the spill. Bue et al. (1998) explained this observation by demonstrating a delayed effect on gamete quality in adults returning to contaminated streams. Murphy et al.'s (2000) observations of oil on the stream banks indicate that 1991 brood embryos were probably also suffering from lethal exposures to PAHs derived from lingering oil reservoirs. Thus, the effects of chronic exposure to oil in their natal habitat probably led to immediate and delayed mortality combined with reduced fitness associated with impaired reproductive ability.

Delayed effects such as those described here may also exacerbate the catastrophic effects experienced by populations after an oil spill. An example can be drawn from the examination of the population level effects of the 'Exxon Valdez' oil spill on Prince William Sound pink salmon. Geiger et al. (1996) estimated that 60000 adult pink salmon from the 1989 brood year failed to return as a result of oil exposure during embryonic development, based on the assumption that $6 \%$ of the 1.91 million fish returning to the southwestern district of Prince William Sound had been affected by the oil. We observed a $15 \%$ reduction in marine survival of fish exposed to the $<5.2$ dose. If we assume a $15 \%$ reduction in survival in the 114000 (i.e. $6 \% \times 1.91$ million) fish that survived incubation in oiled gravel, then escapement should have been 134000 fish and delayed effects should account for the loss of another 20000 fish. Consequently, the estimated losses of 1989 brood pink salmon resulting from exposure to toxic levels of PAHs may have significantly underestimated the actual losses. Delayed effects of PAH exposure in post-emergent fry have also been shown to have the potential for much larger impacts than are indicated by short-term studies of mortality. Growth was reduced for the 1988 brood juvenile salmon in Prince William Sound due to oil contamination in their marine habitats in the spring of 1989 (Wertheimer \& Celwycz 1996, Willette 1996). Geiger et al. (1996) estimated that nearly 2.0 million adult fish were lost from this brood due to reduced growth of the juveniles as they migrated through oilcontaminated water in the weeks following the spill. 
Demonstration of the delayed effects of embryonic exposure to PAHs indicates that 'effective' concentrations of PAHs are lower than predicted by traditional approaches to toxicity testing. 'Effective' concentrations, as determined by typical acute and chronic toxicity assays, represent concentrations that elicit responses when applied over time periods that are short relative to the lives of the exposed animals. Acute and chronic toxicity assays performed in this way are useful for comparing the potencies of compounds or relative sensitivities of organisms (Bliss 1952), but they inaccurately portray the lowest concentrations that can impair the prosperity of exposed organisms (Beak 1958). For example, Cranford et al. (1999) note that acute toxicity testing indicates barite to be toxicologically inert, but sea scallops Placopecten magellanicus exposed to a $0.5 \mathrm{ppm}$ concentration for $68 \mathrm{~d}$ ceased gonad growth. When longer-term exposures and evaluations are used, concentrations with meaningful impacts are often much lower than those predicted by short-term testing (Moles 1998). However, even longer-term 'chronic exposure' tests may not provide a meaningful lowest effective concentration if inappropriate life stages are tested. Billiard et al. (1999) reported that rainbow trout exposed to a $180 \mathrm{ppb}$ concentration of retene between eyeing and hatching experienced decreased growth after swim-up, which would probably result in reduced survival, as it did for the pink salmon described here. Comparison of our results with those of Billiard et al. (1999) suggests that exposure prior to hatching may have resulted in impacts at even lower concentrations.

Reliance on toxicity tests that fail to realistically simulate exposure conditions is likely to misguide waterquality managers. Exposures in the natural environment usually involve multiple life stages exposed to much lower levels of contaminants over greater amounts of time than presumed by acute and chronic toxicity assays. The resultant effects are subsequently played out over the lives of the exposed organisms, which usually represent much longer time scales than $96 \mathrm{~h}$ or even $30 \mathrm{~d}$. Attempts to evaluate toxicity by artificially limiting the exposure and evaluation times can result in misleading conclusions, such as pink salmon eggs being less sensitive to oil effects than other life stages (Rice et al. 1975). While that conclusion may have been appropriate for the immediate consequences of a $96 \mathrm{~h}$ exposure, it fails to inform us about the effects of oil spills on pink salmon. Nevertheless, Brannon \& Maki (1996) relied on that conclusion to evaluate the potential impacts of the 'Exxon Valdez' oil spill on pink salmon. Not surprisingly, they concluded that oil concentrations in the incubating environments were insufficient to cause deleterious effects, despite numerous reports to the contrary.
The basic assumptions regarding the effects of oil spills on subsurface aquatic organisms lie at the root of this misguided reliance on short-term toxicity testing. Most testing proceeds from the assumption that subsurface organisms are most impacted by the rapid dissolution of the volatile mono-aromatic hydrocarbons into the water column below the oil slick. Consequently, much effort has been directed at demonstrating the toxicity of dissolved mono-aromatics. However, these tests only confirm that the water-soluble fraction can be toxic, they provide no information on the risk to aquatic organisms relative to PAHs, and therefore are blunt tools for evaluating the impacts of oil spills. The large-scale study recently described by Birtwell et al. (1999) demonstrates that these assumptions continue to shape the discussion of oil toxicity to subsurface organisms, despite the growing evidence that PAHs not mono-aromatics were the primary cause of fish mortality after the 'Exxon Valdez' oil spill (Rice et al. 1999). Thus, short-term toxicity tests remain the workhorse of managers evaluating the risk and impacts of oil spills on aquatic species despite mounting evidence for the importance of long-term impacts and delayed effects.

Contrary to the supposition that PAHs have a minor impact on subsurface organisms, population productivity is apt to be reduced wherever developing fish embryos encounter PAHs, at low ppb levels. Previous reports have shown immediate effects on teleost embryo survival at concentrations near 1.0 ppb (Carls et al. 1999, Heintz et al. 1999). In this report, we have shown that fish that survive embryonic exposure to PAH concentrations of $<5.2 \mathrm{ppb}$ have lower probabilities of survival to maturity. Those that survive to maturity can be expected to have reduced reproductive output, as demonstrated for minnows that survived embryonic exposure to concentrations of benzo-a-pyrene as low as $1.0 \mathrm{ppb}$ (White et al. 1999), or pink salmon after the 'Exxon Valdez' oil spill (Bue et al. 1998). Consequently, fish populations whose natal habitats are contaminated with PAHs at low ppb levels can be expected to experience the compound effects of mortality during exposure, reduced survivorship afterwards, and reduced reproductive output at maturity. The broad overlap between fish nursery habitats and sites with elevated $\mathrm{PAH}$ loads is therefore a cause for concern.

Acknowledgements. A large number of people were involved in evaluating and marking the fish used in these experiments. We wish to extend a hearty thank-you to those of you who had the good humor to withstand endless days of excising fins from hundreds of thousands of tiny fish, and to the chemists whose excellent skills were central to the success of this project. This work was funded by the 'Exxon Valdez' Oil Spill Trustee Council. However, the conclusions presented by the authors are their own, and do not necessarily reflect those of the Trustee Council. 


\section{LITERATURE CITED}

Beak TW (1958) Tolerance of fish to toxic pollution. J Fish Res Board Can 15(4):559-572

Bence AE, Burns WA (1995) Fingerprinting hydrocarbons in the biological resources of the Exxon Valdez oil spill area. In: Wells PG, Butler JN, Hughes JS (eds) Exxon Valdez oil spill: fate and effects in Alaskan waters, ASTM STP 1219. American Society for Testing and Materials, Philadelphia, p 84-140

Billiard SM, Querbach K, Hodson PV (1999) Toxicity of retene to early life stages of two freshwater fish species. Environ Toxic Chem 18(9):2070-2077

Birtwell IK, Fink R, Brand D, Alexander R, McAllister CD (1999) Survival of pink salmon (Oncorhynchus gorbuscha) fry to adulthood following a 10-day exposure to the aromatic hydrocarbon water-soluble fraction of crude oil and release to the Pacific Ocean. Can J Fish Aquat Sci 56(11): 2087-2098

Bliss CI (1952) The statistics of bioassay: with special reference to the vitamins. Academic Press Inc, New York

Brannon EL, Maki AW (1996) The Exxon Valdez oil spill: analysis of impacts on the Prince William Sound pink salmon. Rev Fish Sci 4(4):289-337

Brannon EJ, Maki AW, Gilbertson LG, Moulton LL, Skalski JR (1995) An assessment of oil-spill effects on pink salmon populations following the Exxon Valdez oil spill. Part 1. Early life history. In: Wells PG, Butler JN, Hughes JS (eds) Exxon Valdez oil spill: fate and effects in Alaskan waters, ASTM STP 1219. American Society for Testing and Materials, Philadelphia, p 585-625

Brown ED, Baker TT, Hose JE, Kocan RM, Marty GD, McGurk M, Norcross BL, Short J (1996) Injury to the early life history stages of Pacific herring in Prince William Sound after the Exxon Valdez oil spill. Am Fish Soc Symp 18:448-462

Bue BG, Sharr S, Moffitt SD, Craig AK (1996) Effects of the Exxon Valdez oil spill on pink salmon embryos and preemergent fry. Am Fish Soc Symp 18:619-627

Bue BG, Sharr S, Seeb JE (1998) Evidence of damage to pink salmon populations inhabiting Prince William Sound, Alaska, two generations after the Exxon Valdez oil spill. Trans Am Fish Soc 127:35-43

Carls MG, Rice SD, Hose JE (1999) Sensitivity of fish embryos to weathered crude oil. Part 1. Low-level exposure during incubation causes malformations, genetic damage, and mortality in larval Pacific herring (Clupea pallasi). Environ Toxic Chem 18(3):481-493

Cranford PJ, Gordon DC Jr, Lee K, Armsworthy SL, Tremblay GH (1999) Chronic toxicity and physical disturbance effects of water- and oil-based drilling fluids and some major constituents on adult sea scallops (Placopecten magellanicus). Mar Environ Res 48:225-256

Geiger HJ, Bue BG, Sharr S, Wertheimer AC, Willette TM (1996) A life history approach to estimating damage to Prince William Sound pink salmon caused by the Exxon Valdez oil spill. Am Fish Soc Symp 18:487-498

Heintz RA, Short JW, Rice SD (1999) Sensitivity of fish embryos to weathered crude oil. Part II. Increased mortality of pink salmon (Oncorhynchus gorbuscha) embryos incubating downstream from weathered Exxon Valdez crude oil. Environ Toxic Chem 18(3):494-503

Lundvall D, Svanback R, Persson L, Bystrom P (1999) Sizedependent predation in piscivores: interactions between predator foraging and prey avoidance abilities. Can J Fish Aquat Sci 56:1285-1292

Maki AW, Brannon EJ, Gilbertson LG, Moulton LL, Skalsk JR
(1995) An assessment of oil-spill effects on pink salmon populations following the Exxon Valdez oil spill. Part 2. Adults and escapement. In: Wells PG, Butler JN, Hughes JS (eds) Exxon Valdez oil spill: fate and effects in Alaskan waters, ASTM STP 1219. American Society for Testing and Materials, Philadelphia, p 585-625

Marty GD, Short JW, Dambach DM, Willits NH, Heintz RA, Rice SD, Stegeman JJ, Hinton DE (1997) Ascites, premature emergence, increased gonadal cell apotosis, and cytochrome P4501A induction in pink salmon larvae continuously exposed to oil-contaminated gravel during development. Can J Zool 75:989-1007

Moles A (1998) Sensitivity of ten aquatic species to longterm crude oil exposure. Bull Environ Contam Toxic 61: 102-107

Moles A, Babcock MM, Rice SD (1987) Effects of oil exposure on pink salmon, Oncorhynchus gorbuscha, alevins in a simulated intertidal environment. Mar Environ Res 21: 49-58

Murphy ML, Heintz RA, Short JW, Larsen ML, Rice SD (2000) Recovery of pink salmon spawning areas after the Exxon Valdez oil spill. Trans Am Fish Soc 128:909-918

Peterson CH, McDonald LL, Green RH, Erickson WP (2001) Sampling design begets conclusions: the statistical basis for detection of injury to and recovery of shoreline communities after the Exxon Valdez oil spill. Mar Ecol Prog Ser (in press)

Rice SD, Moles A, Short JW (1975) The effect of Prudhoe Bay crude oil on survival and growth of eggs, alevins, and fry of pink salmon Oncorhynchys gorbuscha. In: Proceedings of the Joint Conference on Prevention and Control of Oil Spills. American Petroleum Institute. Washington, DC, p 667-670

Rice SD, Thomas RE, Heintz RA, Moles A, Carls MG, Murphy ML, Short JW, Wertheimer AC (1999) Synthesis of longterm impacts to pink salmon following the Exxon Valdez oil spill: persistence, toxicity, sensitivity and controversy. Exxon Valdez Oil Spill Restoration Project Final Report US Department of Commerce, National Oceanic and Atmospheric Administration, National Marine Fisheries Service, Auke Bay laboratory, Juneau, Alaska

Rosenthal H, Alderdice DF (1976) Sublethal effects of environmental stressors, natural and pollutional, on marine fish eggs and larvae. J Fish Res Board Can 33:2047-2065

Roy NK, Stabile J, Seeb JE, Habicht C, Wirgin I (1999) High frequency of K-ras mutations in pink salmon embryos experimentally exposed to Exxon Valdez oil. Environ Toxic Chem 18(7):1521-1528

Sharp D, Sharr S, Peckham C (1994) Homing and straying patterns of coded-wire tagged pink salmon in Prince William Sound. Alaska Sea Grant Rep 94-02:77-82

Short JW, Harris PM (1996) Chemical sampling and analysis of petroleum hydrocarbons in near-surface seawater of Prince William Sound after the Exxon Valdez oil spill. Am Fish Soc Symp 18:17-28

Short JW, Heintz RA (1997) Identification of Exxon Valdez oil in sediments and tissues from Prince William Sound and the Northwestern Gulf of Alaska based on a PAH weathering model. Environ Sci Technol 31:2375-2384

Short JW, Jackson TJ, Larsen ML, Wade TL (1996) Analytical methods used for the analysis of hydrocarbons in crude oil, tissues, sediments, and seawater collected for the natural resources damage assessment of the Exxon Valdez oil spill. Am Fish Soc Symp 18:140-148

Wertheimer AC, Celewycz AG (1996) Abundance and growth of juvenile pink salmon in oiled and non-oiled locations of western Prince William Sound after the Exxon Valdez oil spill. Am Fish Soc Symp 18:518-532 
Wertheimer AC, Rice SD, Thedinga JF, Heintz RA, Bradshaw RF, Maselko JM, Celewycz AG (1997) Effects of oiled incubation substrate on straying and survival of wild pink salmon. Exxon Valdez Oil Spill Restoration Project Annual Report. Exxon Valdez Oil Spill Trustees, Anchorage, Alaska (Restoration Project 96076)

Wertheimer AC, Heintz RA, Thedinga J, Maselko J, Rice SD (2000) Straying behavior of adult pink salmon (Oncorhynchus gorbuscha) exposed as embryos to weathered

Editorial responsibility: Otto Kinne (Editor),

Oldendorf/Luhe, Germany
Exxon Valdez crude oil. Trans Am Fish Soc 129:989-1004 White PA, Robitaille S, Rasmussen JB (1999) Heritable reproductive effects of benzo[a]pyrene on the fathead minnow (Pimephales promelas). Environ Toxic Chem 18(8): $1843-1847$

Willette M (1996) Impacts of the Exxon Valdez oil spill on the migration, growth, and survival of juvenile pink salmon in Prince William Sound. Am Fish Soc Symp 18: $533-550$

Submitted: February 16, 2000; Accepted: June 8, 2000

Proofs received from author(s): October 27, 2000 